Purdue University

Purdue e-Pubs

CTRC Research Publications

Cooling Technologies Research Center

2001

\title{
Local Heat Transfer Distributions in Confined Multiple Air Jet Impingement
}

S V. Garimella

Purdue University, sureshg@purdue.edu

V.P. Schroeder

Follow this and additional works at: http:/ / docs.lib.purdue.edu/coolingpubs

Garimella, S V. and Schroeder, V. P., "Local Heat Transfer Distributions in Confined Multiple Air Jet Impingement" (2001). CTRC Research Publications. Paper 299.

http://dx.doi.org/10.1115/1.1371923

This document has been made available through Purdue e-Pubs, a service of the Purdue University Libraries. Please contact epubs@purdue.edu for additional information. 


\author{
Suresh V. Garimella \\ School of Mechanical Engineering, \\ Purdue University, \\ West Lafayette, IN 47907-1288 \\ e-mail: sureshg@ecn.purdue.edu \\ Vincent P. Schroeder \\ Department of Mechanical Engineering, \\ University of Wisconsin-Milwaukee, \\ Milwaukee, WI 53201
}

\section{Local Heat Transfer Distributions in Confined Multiple Air Jet Impingement}

Heat transfer from a discrete heat source to multiple, normally impinging, confined air jets was experimentally investigated. The jets issued from short, square-edged orifices with still-developing velocity profiles on to a foil heat source which produced a constant heat flux. The orifice plate and the surface containing the heat source were mounted opposite each other in a parallel-plates arrangement to effect radial outflow of the spent fluid. The local surface temperature was measured in fine increments over the entire heat source. Experiments were conducted for different jet Reynolds numbers $(5000<$ Re $<20,000)$, orifice-to-target spacing $(0.5<H / d<4)$, and multiple-orifice arrangements. The results are compared to those previously obtained for single air jets. A reduction in orifice-to-target spacing was found to increase the heat transfer coefficient in multiple jets, with this effect being stronger at the higher Reynolds numbers. With a nine-jet arrangement, the heat transfer to the central jet was higher than for a corresponding single jet. For a four-jet arrangement, however, each jet was found to have stagnationregion heat transfer coefficients that were comparable to the single-jet values. The effectiveness of single and multiple jets in removing heat from a given heat source is compared at a fixed total flow rate. Predictive correlations are proposed for single and multiple jet impingement heat transfer. [DOI: 10.1115/1.1371923]

Keywords: Jet Impingement, Air Jets, Multiple Jets, Electronics Cooling

\section{Introduction}

The enhanced heat and mass transfer rates obtained through the use of impinging jets have made them an attractive alternative in industrial applications ranging from the annealing of steel to the drying of paper and textiles, food processing, and the thermal management of electronics. While a large number of studies of jet impingement exist in the literature, relatively limited information is available regarding confined jet impingement, where the outflow is confined to a parallel-plates arrangement. Few studies have considered arrays of confined jets and compared their performance to that of single jets at a given flow rate, pressure drop, or pumping power.

The present work investigates the local heat transfer distribution under arrays of multiple air jets, and is a follow-up to a previous study [1] which reported local heat transfer coefficients for single jets. The heat source is small and square, and the orifices are square-edged and short, thus giving rise to stilldeveloping velocity profiles. In addition, the separation between the orifice plate and the heat source is small $(\leqslant 4 d)$ to ensure truly confined impingement. Jet impingement heat transfer and fluid mechanics for single liquid jets has also been investigated as part of this research program $[2,3,4]$.

The local heat transfer to an array of impinging jets is a complex function of Reynolds number, orifice-target spacing, number of jets, interjet spacing, and outflow (exhaust) configuration. Huber and Viskanta [5,6] investigated the effects of orifice-target separation and Reynolds number on the heat transfer to an array of nine confined air jets. At large orifice-target spacings, a single jet yielded higher heat transfer coefficients than jets in the array for a given Reynolds number and $H / d$. For $H / d<1$, the local Nusselt numbers for the jet arrays became similar in magnitude to those for a single jet at the same Reynolds number. As the orifice-

Contributed by the Electronic and Photonic Packaging Division for publication in the JOURNAL OF ELECTRONIC PACKAGING. Manuscript received by the EPPD November 1998; revised manuscript received December 26, 2000. Associate Editor: D. Agonafer. target spacing was decreased from 6 to 1 jet diameters, the local Nusselt number increased everywhere throughout their experimental range of $r / d \leqslant 3$. In addition, secondary peaks were observed at $r / d \approx 0.5$ and 1.6 when $H / d<1$. The inner peak was attributed to a local thinning of the boundary layer, while the outer peak was said to be due to a transition to a turbulent wall jet.

The interjet spacing is a significant factor affecting the local heat transfer coefficient, primarily by influencing the neighboringjet interactions [6,7]. Huber and Viskanta [6] found that at their larger orifice-target spacings $(H / d=1,6)$, an interjet spacing of 8 resulted in higher local Nusselt numbers than smaller interjet spacings of 4 and 6. Furthermore, all the interjet spacings tested showed lower local Nusselt numbers than for a single jet at the same Reynolds number (for $H / d \geqslant 1$ ). An interjet spacing of four diameters was found to provide the highest average heat transfer over a given surface area.

Goldstein and Timmers [8] obtained contour plots of the local heat transfer coefficient due to impinging arrays of three (collinear) and seven (hexagonal) jets at a constant Reynolds number. It was observed that with both array configurations, secondary maxima occurred between the jets. Gardon and Cobonpue [9] and Behbahani and Goldstein [10] also observed secondary maxima between jets. Pan and Webb [11] attributed the secondary maxima to boundary layer separation and eddying of the flows as a result of wall-jet interaction between the impinging jets, while Slayzak et al. [12] related these peaks to the amount of momentum retained by the interacting wall jets. Pan and Webb also reported that the strength of the intervening maxima increased with Reynolds number, that the maxima are stronger at smaller orificetarget spacings, and that the strongest secondary maxima occur for small interjet spacings.

Obot and Trabold [7] investigated the effect of exhaust configuration on the heat transfer for an array of jets by constraining the outflow to two opposing directions (instead of being radial). The local heat transfer coefficients were seen to decrease as the crosssectional area available for outflow was decreased. Huber and 
Viskanta [6] and Hollworth and Dagan [13] found that placing spent air exits (located in the orifice plate) increased the average heat transfer for the array by as much as $20-30$ percent, especially at higher Reynolds numbers and smaller orifice-target spacings. The increase was attributed to improved exhaust which in turn served to reduce the degrading effects of radial cross flow from neighboring jets.

In the present study, the local heat transfer from multiple confined air jets is obtained as a function of jet Reynolds number $(\operatorname{Re})$, orifice-heat source spacing $(H)$, and interjet spacing $(S)$, with the outflow confined to a parallel-plates arrangement. The pressure drop across the orifices was measured in all cases. Predictive correlations are proposed in terms of the governing nondimensional parameters, and are compared to those in the literature. In ongoing work, confined air jet impingement heat transfer in conjunction with surface enhancement is being investigated.

\section{Experimental Setup and Procedures}

A schematic of the air jet impingement facility used for the experiments in this study is shown in Fig. 1. A regenerative blower with a variable-speed drive is the prime mover. The pressurized air is metered by one of three flowmeters mounted in parallel. A heat exchanger mounted downstream of the blower is used to maintain the exit temperature of the jet to within $\pm 0.2^{\circ} \mathrm{C}$ of the desired value. Several valves, in conjunction with the variable-speed motor drive controller, help to set the required flow rate.

The test section consists of a cylindrical plenum, the bottom of which is designed to accept interchangeable orifice plates, and a traversable target plate that contains the heat source. A series of screens and honeycomb in the plenum serve to condition the flow. The desired orifice-heat source separation distance $(H)$ between the plenum and the target plate is set using three high-precision gage blocks in a triangular arrangement to ensure parallelism between the orifice plate and the target surface. Details of the test section are presented in [1].

The temperature of the air jet is measured using a 36 gage T-type thermocouple positioned just prior to the plenum exit. Three different multiple-orifice arrangements were investigated: two arrays of nine 1.59 and four $3.18 \mathrm{~mm}$ diameter orifices with interjet spacing $S / d=4$ (hereafter referred to as the $9 \times 1.59 \mathrm{~mm}$ and $4 \times 3.18 \mathrm{~mm}$ arrays), and one array of four $3.18 \mathrm{~mm}$ diameter orifices with $S / d=3$. The thickness of each orifice plate was equal to the diameter of the orifice (orifice length-to-diameter aspect ratio $l / d=1)$. Air from the orifice plate impinges on to a square, stainless steel foil heat source $(20 \times 20 \mathrm{~mm})$, which is mounted in the target plate. The heat source design is identical to that used in [2], and further details are not provided here.

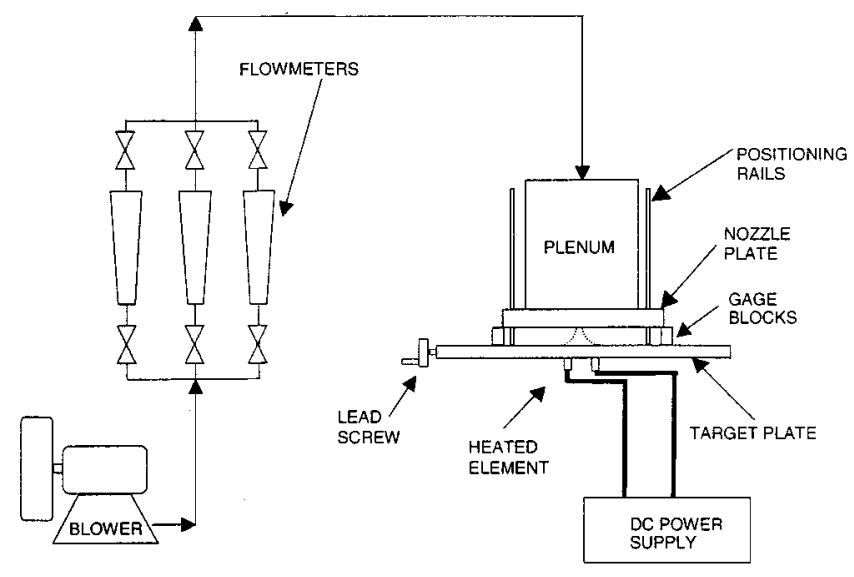

Fig. 1 Schematic diagram of the air jet impingement experimental facility
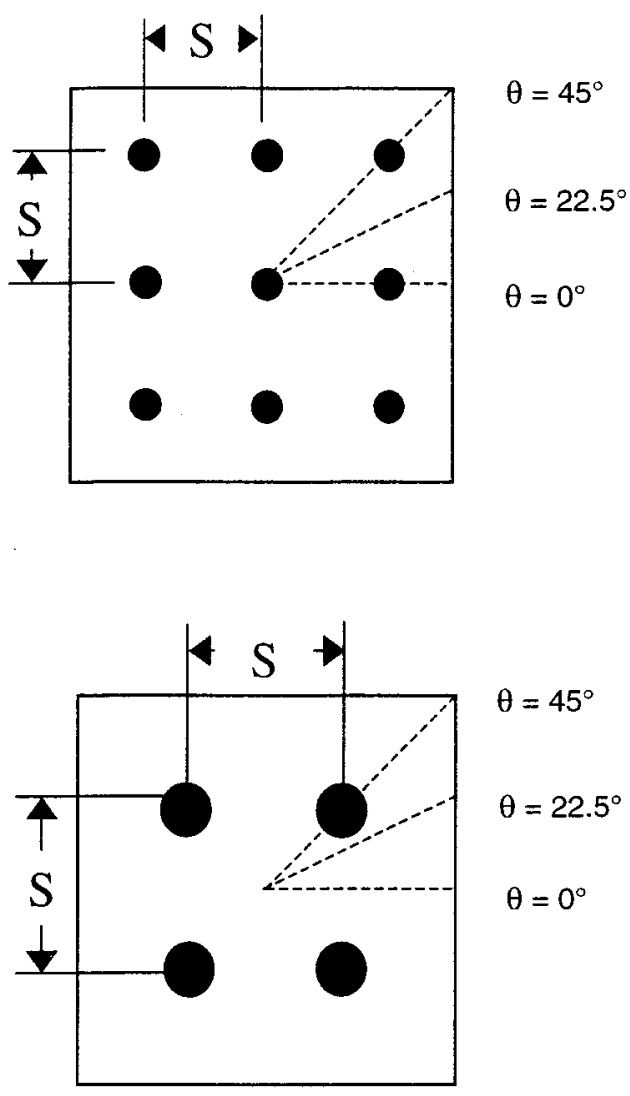

Fig. 2 Jet arrays and heat source orientation for the multiplejet experiments

The heat source (with a thermocouple mounted on its underside at the center) is moved laterally with respect to the center of the orifice array, along three different rays (Fig. 2), thus mapping the local surface temperature distribution, in minimum increments of $0.01 \mathrm{~mm}$. These measurements were obtained by rotating the orifice plate within the plenum assembly, thereby rotating the jets to a different orientation with respect to the heat source. Measurements along each ray were made only over one-half of the heated surface, since the temperature distributions were found to be symmetric about the center of the heater. The temperature measurements obtained over the octant of the heat source surface shown (Fig. 2) are repeated over the rest of the heat source and used in computing area-averaged heat transfer coefficients.

The voltage drop across the heat source was measured using solid copper wires with soldered terminal ends that are attached to the ends of the bus bars to which the foil heater is brazed. The current is determined from the voltage drop across a calibrated resistance shunt mounted in series with the cable. Analysis using temperatures measured at the top and bottom of the insulation layer underneath the foil heater showed the power loss by conduction to be typically 4 percent of the supply power. Radiation losses were estimated to be always less than 1 percent of the supply power. These losses $\left(Q_{\text {loss }}\right)$ were incorporated into the data reduction program and subtracted from the total power dissipation $\left(Q_{\text {in }}\right)$. The local heat transfer coefficient was calculated from:

$$
h=\frac{Q_{\text {in }}-Q_{\text {loss }}}{A_{h}\left(T_{s}-T_{j}\right)}=\frac{q_{s}^{\prime \prime}}{\left(T_{s}-T_{j}\right)}
$$

where the heat flux $q_{s}^{\prime \prime}$ and jet temperature $\left(T_{j}\right)$ are constant, and 
the local surface temperature $\left(T_{s}\right)$ depends on location on the heat source. The results from each experiment were also area-averaged over the $20 \times 20 \mathrm{~mm}$ heat source area to obtain an average heat transfer coefficient

$$
\bar{h}=\frac{q_{s}^{\prime \prime} A_{h}}{\sum A_{i}\left(T_{s}-T_{j}\right)}
$$

The difference between the surface-average heat source temperature and the jet temperature $\left(\bar{T}_{s}-T_{j}\right)$ was held constant in all tests at approximately $15^{\circ} \mathrm{C}$. Additional details of the heat-source construction and heat transfer coefficient calculations are available in [14].

A standard uncertainty analysis showed the uncertainty at 95 percent confidence in the heat transfer coefficient to be less than 4.5 percent. The uncertainty in the Nusselt number was slightly higher (5.6 percent) due to the uncertainty in the orifice diameter. The largest contribution to the uncertainty comes from the temperature measurement $\left( \pm 0.3^{\circ} \mathrm{C}\right)$; uncertainty in the heat source surface area was estimated at 0.28 percent. All the results exhibited a high degree of symmetry about the center of the heat source.

\section{Results and Discussion}

General features of the heat transfer from confined multiple jets are first discussed and contrasted with single-jet behavior. The effects of orifice-to-target spacing, Reynolds number, and interjet spacing on the local heat transfer distribution under multiple jets are then presented. Predictive correlations are then proposed for confined multiple jet impingement heat transfer and compared to others in the literature. Finally, some important design considerations are explored.

The local heat transfer distribution for the $9 \times 1.59 \mathrm{~mm}$ array is illustrated in Fig. 3 for a jet Reynolds number of 15,000 and an orifice-target spacing of $H / d=4$. The dashed line at $r / d=0$ corresponds to the center of the central jet as well as of the heater; the dashed lines at $r / d=4$ and $4 \sqrt{ } 2$ represent the centers of the adjacent and diagonal impinging jets, respectively. The jet-array data are plotted against distance from the centerline $(r / d)$, and terminate when the end of the heated surface is reached (see Fig. 2). The corresponding single jet heat transfer coefficient distribution for the same Re and $H / d$ is also plotted in the figure for comparison. Data for $r / d<0$ are included in the figures to demonstrate symmetry.

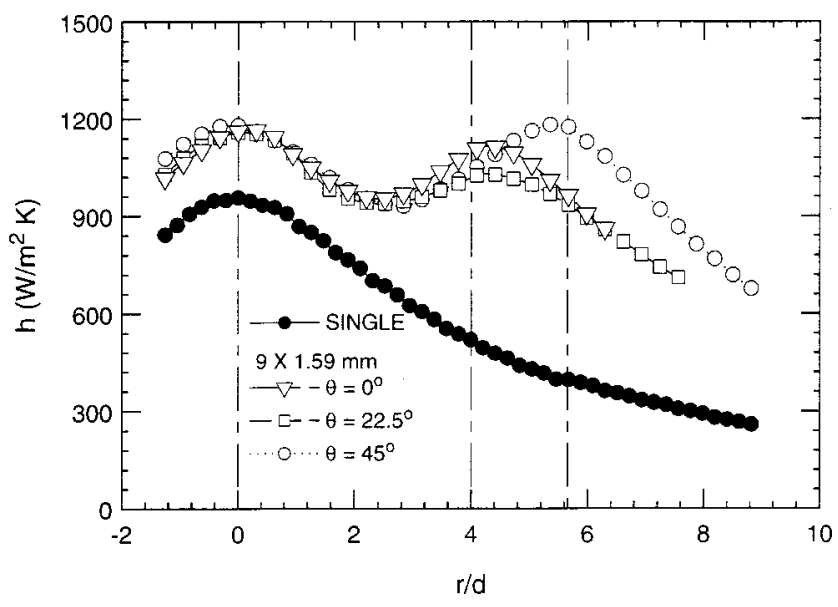

Fig. 3 Local heat transfer coefficient distributions for the 9 $\times 1.59 \mathrm{~mm}$ array (open symbols) at $R e=15,000$ and $H / d=4$. The dashed vertical lines indicate the centers of the array jets located at $r / d=0,4$, and $42(S / d=4)$. Single-jet results at the same Re and $H / d$ are plotted for comparison (solid symbols).

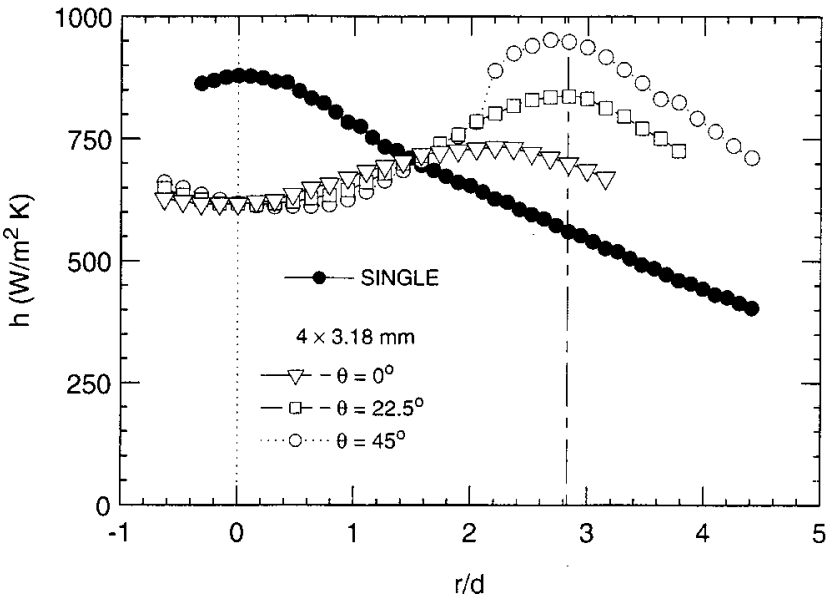

Fig. 4 Local heat transfer coefficient distribution for the 4 $\times 3.18 \mathrm{~mm}$ array (open symbols) at $R e=20,000$ and $H / d=4$. The dashed vertical line indicates the center of any jet in the array, located at $r / d=2 \sqrt{2},(S / d=4)$; the vertical dotted line indicates the center of the heater. Single-jet results at the same Re and $H / d$ are plotted for comparison (solid symbols).

As expected, peaks in the heat transfer coefficient are observed at or very near the $r / d$-locations of the orifice centers $(r / d$ $=0,4$, and $4 \sqrt{ } 2$ ). The local heat transfer coefficient drops off with distance from the stagnation points in a manner similar to that in the single jet distribution. In the region $0 \leqslant r / d \leqslant 2$, the curves for the jet array and the single jet have similar shapes. As $r / d$ increases beyond 2, the array heat transfer coefficients drop slightly, level off, and then increase in magnitude as the presence of the neighboring jets is felt. In contrast, the single jet distribution drops off monotonically with increasing $r / d$ over the entire extent of the heater. The average heat transfer coefficients are markedly different for the two cases: the array configuration is twice as effective at heat removal as the single jet at the same $\operatorname{Re}$ and $H / d$ ( $\vec{h}$ $=883$ versus $442 \mathrm{~W} / \mathrm{m}^{2} \mathrm{~K}$ for the $9 \times 1.59 \mathrm{~mm}$ array and the single jet, respectively).

The local heat transfer distribution for the $4 \times 3.18 \mathrm{~mm}$ array is shown in Fig. 4 for a jet Reynolds numbers of 20,000 and an $H / d$ of 4 . The dotted line at $r / d=0$ corresponds to the center of the single jet and the heater. The dashed line at $r / d=2 \sqrt{2}$ corresponds to the center of any of the jets in the array.

A minimum in the local heat transfer coefficient for the 4 $\times 3.18 \mathrm{~mm}$ array occurs in the center of the heater $(r / d=0)$ due to the absence of a central jet. As $r / d$ increases, the array heat transfer coefficients increase as the stagnation regions of the jets are encountered. The peak in the heat transfer coefficient along $\theta=45^{\circ}$ occurs very near the jet centerline $(r / d=2 \sqrt{ } 2)$. Unlike the nine-jet array of Fig. 3, the $4 \times 3.18 \mathrm{~mm}$ array results in a 20 percent higher average heat transfer coefficient than the single jet at the same $\operatorname{Re}$ and $H / d$ ( $\bar{h}=714$ and $595 \mathrm{~W} / \mathrm{m}^{2} \mathrm{~K}$ for the 4 $\times 3.18 \mathrm{~mm}$ array and the single jet, respectively).

The effect of orifice-to-target spacing on the local heat transfer coefficients for the $9 \times 1.59 \mathrm{~mm}$ array is illustrated for two different jet Reynolds numbers of 15,000 and 5000 in Fig. 5. It is evident that a decrease in the orifice-target spacing from $H / d$ of 4 to 1 results in an increase in heat transfer coefficient for both Reynolds numbers. The effect is stronger at the higher Reynolds number: for a decrease in $H / d$ from 4 to 1 , the percentage increase in average heat transfer coefficient at $\mathrm{Re}=15,000$ is twice (from 883 to $1142 \mathrm{~W} / \mathrm{m}^{2} \mathrm{~K}$ ) the increase at $\mathrm{Re}=5000$ (from 446 to 509 $\mathrm{W} / \mathrm{m}^{2} \mathrm{~K}$ ). This increase in heat transfer for the jet array with decreasing $H / d$ may be explained using the observation of Behbahani and Goldstein [10] who stated that, at small $H / d$, the turbulence intensity of a jet is increased by mixing with the spent flow 


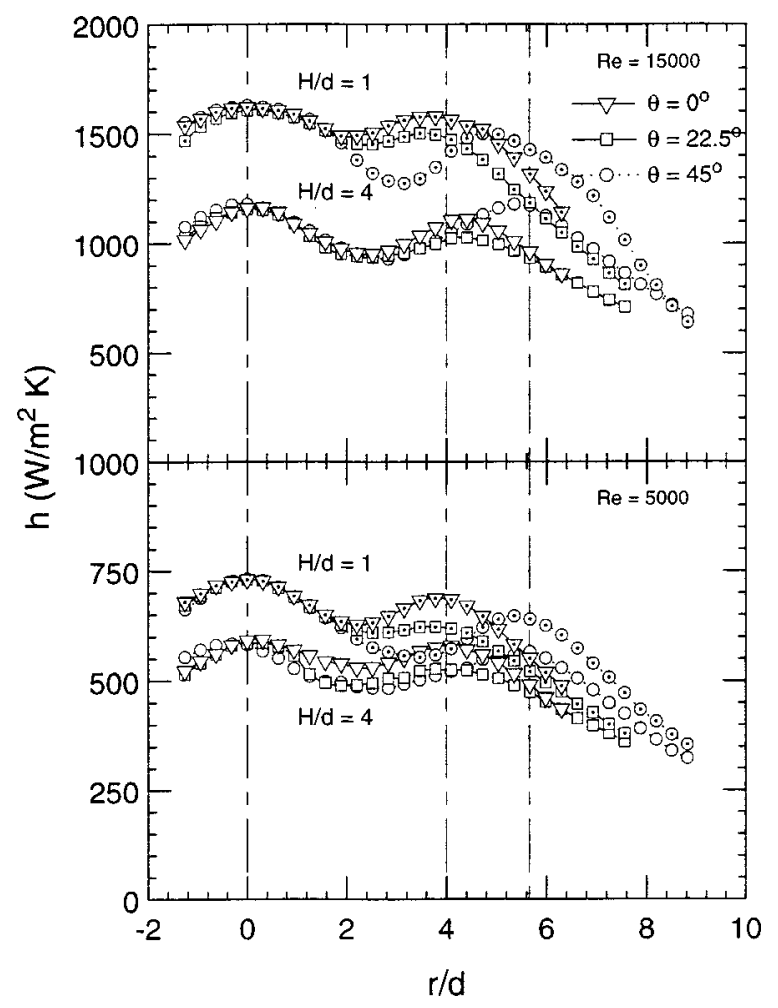

Fig. 5 Variation in the $9 \times 1.59 \mathrm{~mm}$ array heat transfer coefficients with orifice-target spacing for $R e=15,000$ (top) and 5000 (bottom)

from neighboring jets, the effect being similar to a single jet in crossflow. Striegl and Diller [15] also showed that entrainment of warmer air into the jet decreases with smaller $H / d$, increasing the performance of the jet.

Similar trends of variation in the local heat transfer coefficients with orifice-to-target spacing are shown in Fig. 6 for a different jet array $(4 \times 3.18 \mathrm{~mm})$. The heat transfer for $H / d=4$ is compared to that for $H / d=0.5$ at two different jet Reynolds numbers of 20,000 and 5000 in the figure. As with the $9 \times 1.59 \mathrm{~mm}$ jet array, a decrease in $H / d$ for the $4 \times 3.18 \mathrm{~mm}$ jet array results in an increase in the magnitude of the heat transfer coefficients at both Reynolds numbers. The effect is more pronounced at the higher Reynolds number; away from the stagnation regions of the individual jets, the effect of $H / d$ is negligible at $R e=5000$ (note the different scales used for the two plots in the figure). At the higher Reynolds number, a decrease in $H / d$ also causes a shift in the maxima in the local heat transfer coefficient distributions towards the center of the heater $(r / d=0)$ and a flattening of the distributions in the stagnation regions. This behavior may be attributed to flow interactions with the confining orifice plate which create higher levels of turbulence at low $H / d$ [11]. The average heat transfer coefficient is appreciably larger at the lower $H / d$ (e.g., for $\operatorname{Re}=20,000, \bar{h}$ $=714 \mathrm{~W} / \mathrm{m}^{2} \mathrm{~K}$ at $H / d=4$ compared to $869 \mathrm{~W} / \mathrm{m}^{2} \mathrm{~K}$ at $H / d$ $=0.5)$; however, the heat transfer distribution over the heat source is more uneven at the smaller $H / d$.

The influence of Reynolds number on the local heat transfer coefficients is explored in Fig. 7 which shows results for the 9 $\times 1.59 \mathrm{~mm}$ array for $\mathrm{Re}=15,000$ and 5000 at two different spacings of $H / d=4$ and 1 . Corresponding single-jet results at the same Re and $H / d$ are also included for comparison. As the Reynolds number is increased at a fixed $H / d$, the local heat transfer coefficients also increase, as expected. The $H / d=4$ spacing is characterized by distinct peaks in heat transfer coefficient at the locations of the centers of the jets $(r / d=0 ; r / d=4: \theta=0$; and $r / d$ $\left.=4 \sqrt{ } 2: \theta=45^{\circ}\right)$. The distribution is flatter for the smaller spacings

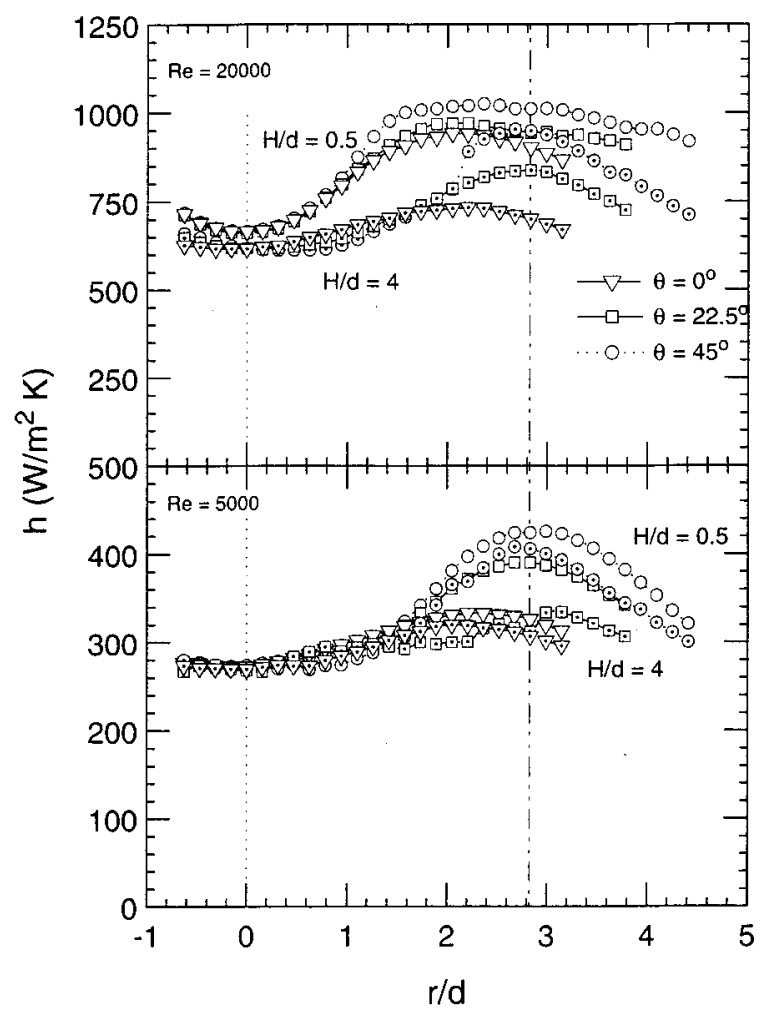

Fig. 6 Variation in the $4 \times 3.18 \mathrm{~mm}$ array heat transfer coefficients with orifice-target spacing for $R e=20,000$ (top) and 5000 (bottom)

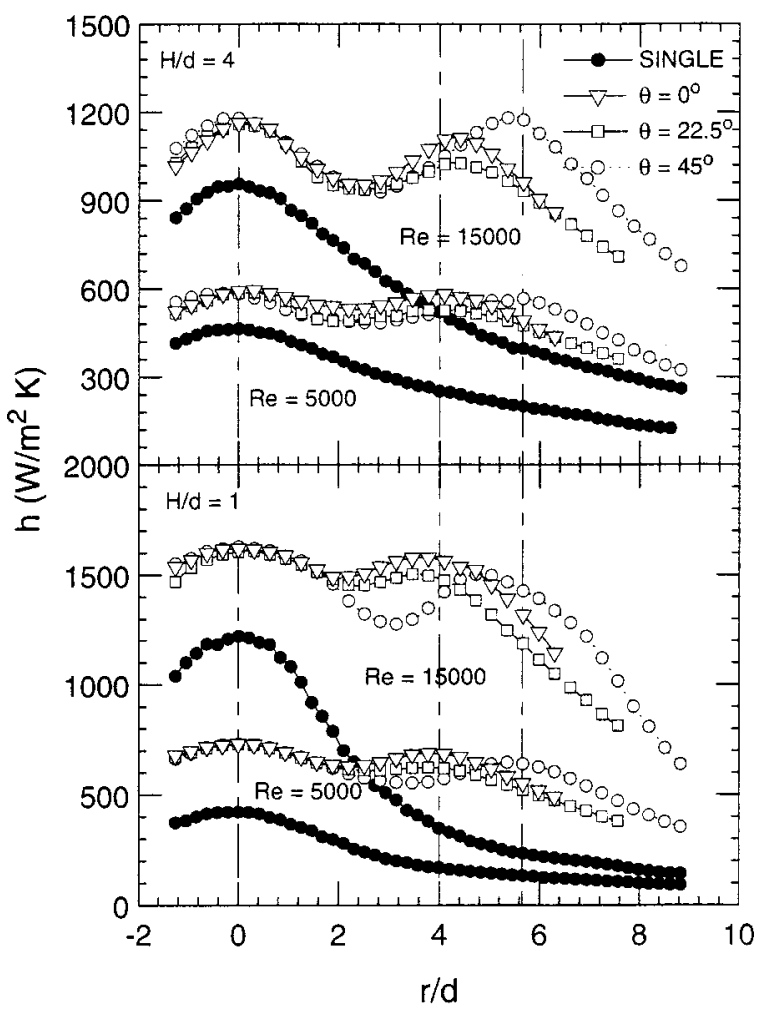

Fig. 7 Effect of Reynolds number on the $9 \times 1.59 \mathrm{~mm}$ array heat transfer coefficients for $H / d=4$ (top) and 1 (bottom). Single-jet results at the same $R e$ and $H / d$ are plotted for comparison (solid symbols). 


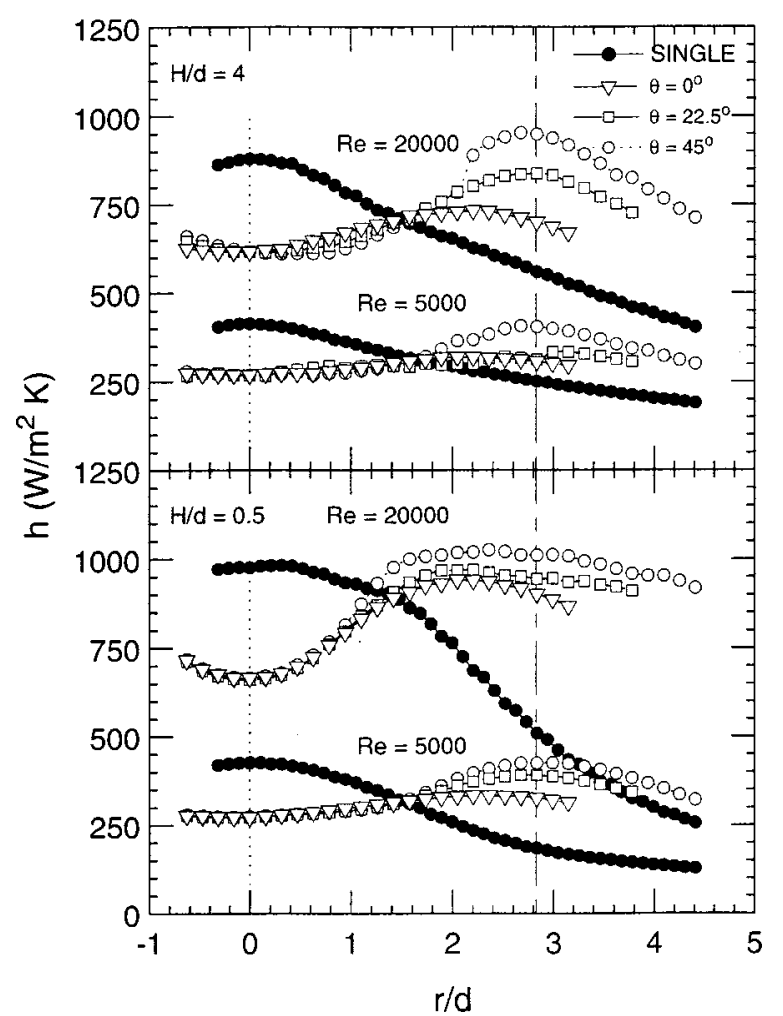

Fig. 8 Effect of Reynolds number on the $4 \times 3.18 \mathrm{~mm}$ array heat transfer coefficients for $H / d=4$ (top) and 0.5 (bottom). Single-jet results at the same $R e$ and $H / d$ are plotted for comparison (solid symbols).

of $H / d=1$, possibly due to an increase in crossflow velocity and turbulence levels at this spacing [8]. The array heat transfer also increases faster with increasing Reynolds number than in the case of the single jet at the smaller $H / d$. the increase in $\bar{h}$ as Reynolds number increases from 5000 to 15,000 with $H / d=1$ is 124 percent for the array but only 87 percent for the single jet. At $H / d$ $=4$, the increase in $\bar{h}$ with Reynolds number is roughly the same $(\approx 100$ percent $)$ for both the array and the single jet. It is also apparent that the stagnation-region heat transfer coefficient for the central jet in the $9 \times 1.59 \mathrm{~mm}$ array exceeds the corresponding (i.e., at the same Re and $H / d$ ) single-jet value in all cases in Fig. 7.

Local heat transfer coefficients for the $4 \times 3.18 \mathrm{~mm}$ jet array are plotted in Fig. 8 to show the effect of Reynolds number for $\mathrm{H} / \mathrm{d}$ $=4$ and 0.5 . As with the $9 \times 1.59 \mathrm{~mm}$ array, the local heat transfer coefficients increase with increasing Reynolds number as expected. Also, as the Reynolds number increases from 5000 to 20,000 , the array $\bar{h}$ increases by 173 percent at $H / d=0.5$, whereas at $H / d=4$, a smaller increase in $\bar{h}$ of 139 percent is observed; this is consistent with the results for the $9 \times 1.59 \mathrm{~mm}$ array. However, in contrast to the $9 \times 1.59 \mathrm{~mm}$ array (where the array heat transfer coefficients were much higher than the single-jet values, Fig. 7), the stagnation heat transfer coefficients are similar in magnitude for jets in the array and the single jet. In this regard, the behavior of both jet arrays considered in this study differs from the observations of Huber and Viskanta [5], who found that array heat transfer coefficients were lower than those for single jets, when compared at the same $\mathrm{Re}$ and $H / d$. The array values in their work approached the single-jet values with increasing Reynolds number as the orifice-target spacing was reduced. This difference may be attributed to the larger heat source used by Huber and Viskanta (their open-area ratio, $f$, was approximately 40 times less than that

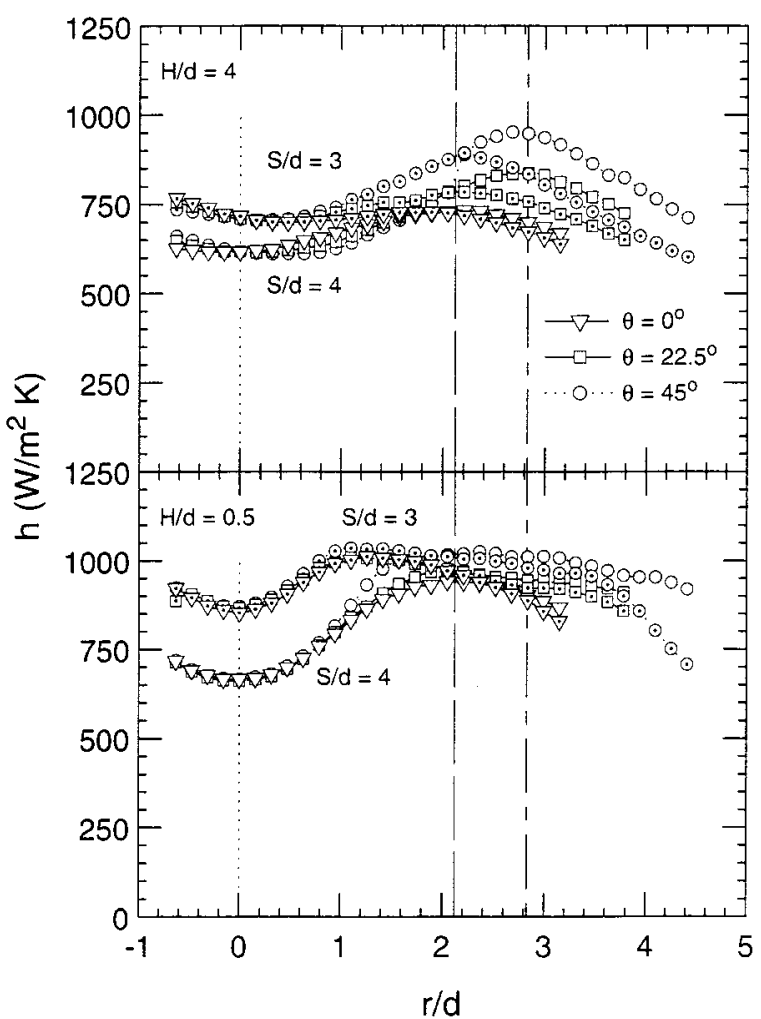

Fig. 9 Influence of interjet spacing $(S / d)$ on the heat transfer coefficient for the $4 \times 3.18 \mathrm{~mm}$ array at $\mathrm{H} / \mathrm{d}=4$ (top) and 0.5 (bottom) and $R e=20,000$

used in the present study). A larger heat source would cause the bulk temperature of the air to rise, degrading the local heat transfer coefficients $[1,15]$.

It has been reported in the literature $[6,11]$ that a decrease in interjet spacing $(S / d)$ in multiple jets results in an increase in area-averaged heat transfer. Results from the present study for two interjet spacings are compared in Fig. 9 where the local heat transfer coefficients for a $4 \times 3.18 \mathrm{~mm}$ array are shown for interjet spacings of $S / d=3$ and 4 at a Reynolds number of 20,000 and $H / d=4$ and 0.5 . (All previous $4 \times 3.18 \mathrm{~mm}$ array results in this paper were shown for $S / d=4)$. At $H / d=0.5$, the heat transfer coefficients for $S / d=3$ are relatively larger over $0 \leqslant r / d \leqslant 2$, but then drop below those for $S / d=4$ for $r / d>2$. The net result is that the average heat transfer coefficients for the two interjet spacings are almost identical $\left(\bar{h}=868\right.$ and $863 \mathrm{~W} / \mathrm{m}^{2} \mathrm{~K}$ for $S / d=3$ and 4 , respectively). In fact, the effect on $\bar{h}$ of changing the interjet spacing between $S / d$ of 3 and 4 was observed to be negligible for all Reynolds numbers and orifice-target spacings considered here, with the difference in $\bar{h}$ between the two interjet spacings being never more than 5 percent.

Predictive Correlations. All the average heat transfer data were correlated as functions of the jet exit velocity in terms of Re, fluid properties (Pr), and orifice-to-target spacing $(H / d)$. All thermodynamic properties were evaluated at the film temperature. The Prandtl number was practically constant throughout the experiments $(\operatorname{Pr} \approx 0.7)$, and its exponent was fixed at 0.4 , a value previously used in the literature for jet impingement $[2,16]$.

As a reference, the single-jet experiments conducted as part of this research program [1] resulted in the following correlation for area-averaged Nusselt number: 


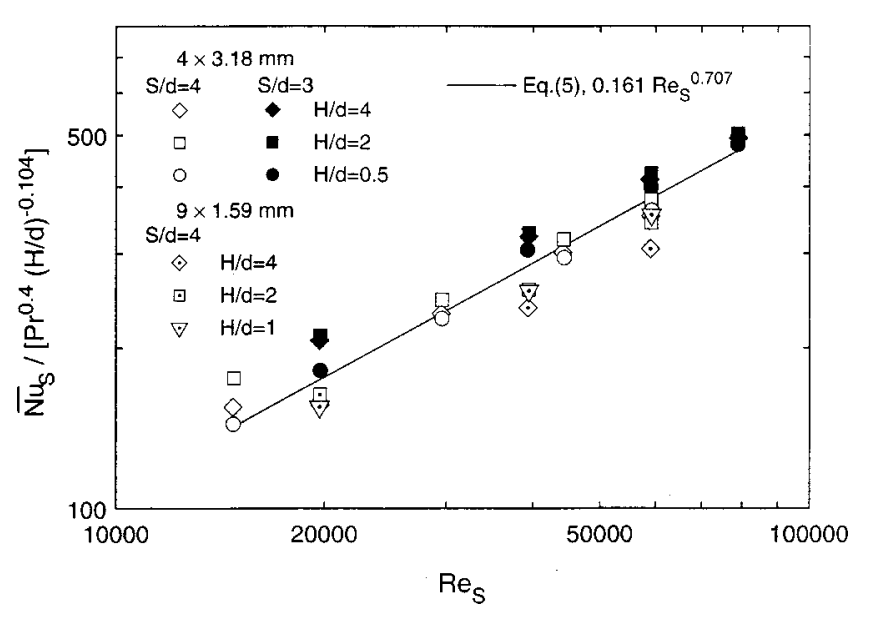

Fig. 10 The proposed correlation for the array area-averaged Nusselt numbers (Eq. 5) and the experimental results for all the tests in this study

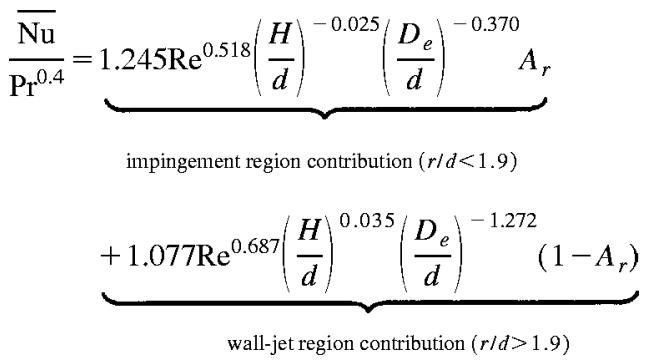

(3)

This equation is valid for $5000 \leqslant \operatorname{Re} \leqslant 20,000,0.5 \leqslant H / d \leqslant 4$, $1.59 \leqslant d \leqslant 12.7 \mathrm{~mm}$ and $l / d=1$. If $A_{r}>1$ (for $d=12.7$ and 6.35 $\mathrm{mm})$, it is set equal to 1 and the wall-jet region components drops out of the equation. Equation (3) predicts the average heat transfer for all the single-jet experiments with average and maximum deviations of 5.2 and 26.3 percent, respectively. If only the $H / d$ $=1$ data for the $1.59 \mathrm{~mm}$ orifice (4 data points) are excluded, the average and maximum deviations drop to 4.5 and 11.4 percent, respectively.

The data for the jet-array configurations were correlated as functions of the Prandtl number, jet Reynolds number $(\mathrm{Re})$ and orifice-to-target spacing $(H / d)$. The effect of interjet spacing $(S / d)$ on the jet-array heat transfer was not adequately characterized in this study to justify its inclusion as a parameter in the correlations. An equation which predicts the multiple-jet areaaveraged Nusselt numbers obtained in the present study with average and maximum deviations of 9 and 28.2 percent is:

$$
\overline{\mathrm{Nu}}=0.127 \operatorname{Re}^{0.693} \operatorname{Pr}^{0.4}\left(\frac{H}{d}\right)^{-0.105}
$$

This equation is valid for $5000 \leqslant \operatorname{Re} \leqslant 20,000,0.5 \leqslant H / d \leqslant 4$, and $l / d=1$ for the $9 \times 1.59 \mathrm{~mm}$ and $4 \times 3.18 \mathrm{~mm}$ arrays.

The interjet spacing, $S$, has also been used as the characteristic length when correlating multiple-jet average Nusselt numbers $[7,17]$. If the multiple-jet results of the present study are correlated with $S$ as the characteristic length, the following correlation is obtained:

$$
\overline{\mathrm{Nu}}_{s}=0.161 \operatorname{Re}_{s}{ }^{0.707} \operatorname{Pr}^{0.4}\left(\frac{H}{d}\right)^{-0.104}
$$

This equation predicts the multiple-jet data with lower deviation than Eq. (4) (average and maximum deviations are 8.6 and 24.3

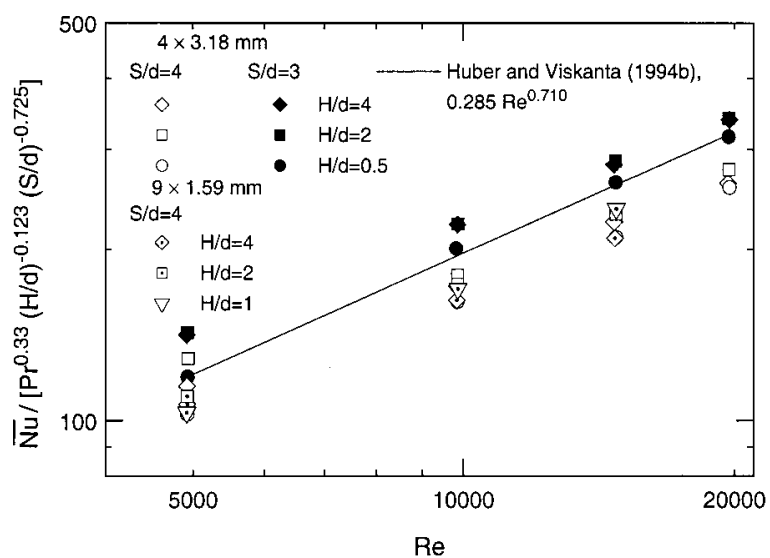

(a)

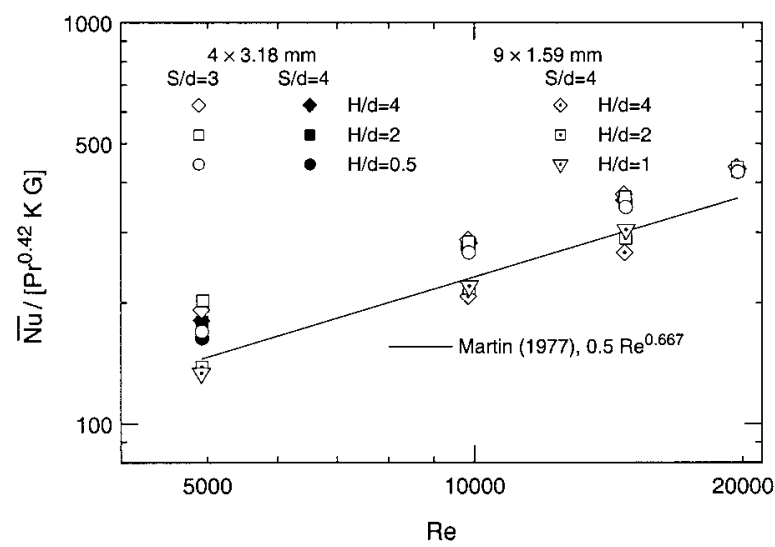

(b)

Fig. 11 Comparison of the area-averaged Nusselt numbers from the present study with the predictions of (a) Huber and Viskanta [6] and (b) Martin [18]

percent, respectively). A comparison of the predicted results from Eq. (5) with the experimental data for average Nusselt number is shown in Fig. 10

Few studies in the literature have presented average heat transfer correlations for confined multiple-jet impingement, especially for the orifice and heat source dimensions investigated here. Martin [18] proposed a correlation based on a collection of unconfined air jet data. Huber and Viskanta [6] also presented a correlation for the heat transfer coefficient averaged over a unit cell in their nine-jet array. In a well-exhausted array, the average heat transfer over the unit cell (with width and length equal to $S$ ) should be similar for each jet in the array; therefore $\bar{h}$ for the unit cell is also the average for the entire array.

The array-average Nusselt number data of the present study are compared with the correlations of Huber and Viskanta [6] and Martin [18] in Figs. 11(a) and (b). Huber and Viskanta's confined-impingement correlation predicts the average Nusselt numbers of the present study to within average and maximum deviations of 12.2 and 24.3 percent, respectively, overpredicting all the data except for the four-jet array at the interjet spacing of $S / d=3$. Spent fluid from the jets in their study was allowed to exit through exhaust ports in the orifice plate, and led to an enhancement in heat transfer; this may account for the overprediction. Martin's correlation for unconfined jets overpredicts the present results for the $9 \times 1.59 \mathrm{~mm}$ array and underpredicts those for the $4 \times 3.18 \mathrm{~mm}$ array. Average and maximum deviations of the experimental results from this correlation are 16.8 and 38.4 percent, respectively. Confinement has been shown to influence the heat transfer coefficient $[19,20,21]$, and may account for some of the difference. Also, Martin's correlation is valid for $4.43 \leqslant S / d \leqslant 14$, whereas the present study considered $S / d=3$ and 4 . 


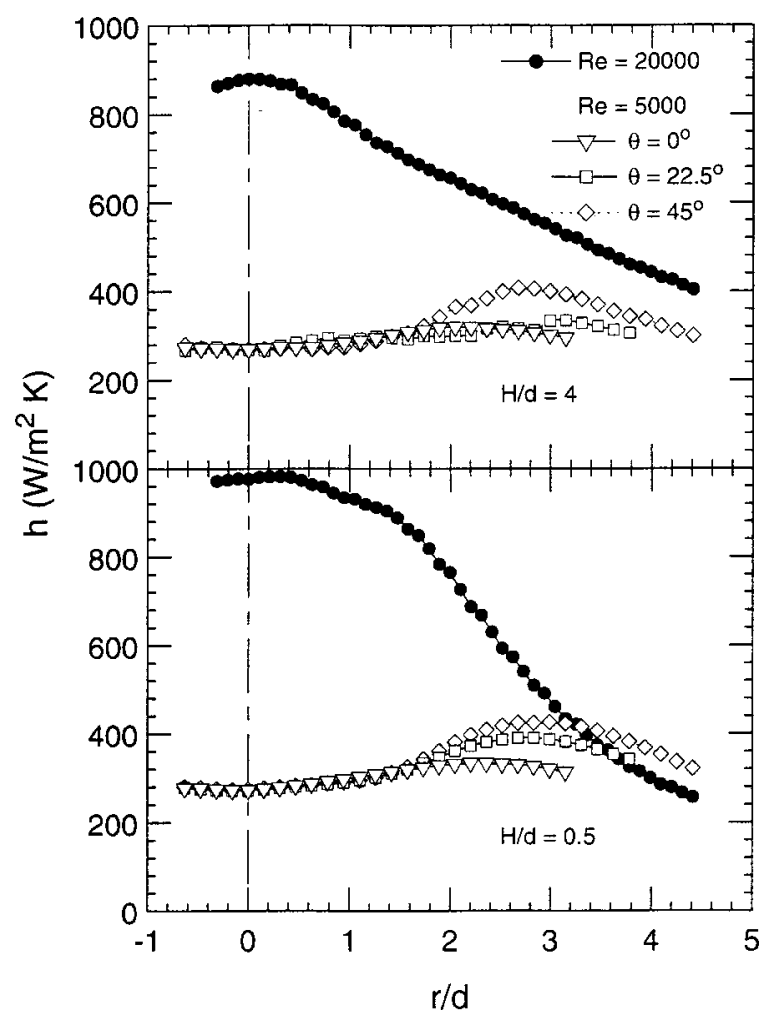

Fig. 12 Comparison of heat transfer coefficients for a single $3.18 \mathrm{~mm}$ jet (solid symbols) with the $4 \times 3.18 \mathrm{~mm}$ jet array (open symbols) at constant flow rate $\left(\dot{m} \approx 9 \times 10^{-04} \mathrm{~kg} / \mathrm{s}\right)$ at $H / d=4$ (top) and 0.5 (bottom)

Design Considerations. Comparisons between the array and single-jet results have thus far been made with the Reynolds number held constant. By definition, this is equivalent to making comparisons at the same pressure drop (measured pressure drop values are listed in Table 1). In these comparisons, the flow rate through the array of jets is $n$ times higher than for the single jet. In designing impingement systems, however, it is often necessary to compare the performance of a single jet versus multiple jets at the same total flow rate. Figure 12 shows such a comparison: local heat transfer coefficients with a $4 \times 3.18 \mathrm{~mm}$ array $(S / d=4)$ are compared to those for a single jet $(d=3.18 \mathrm{~mm})$ at the same flow rate $\left(\dot{m} \approx 9 \times 10^{-4} \mathrm{~kg} / \mathrm{s}\right)$ for $H / d=4$ and 0.5 .

It is clear from Fig. 12 that the $4 \times 3.18 \mathrm{~mm}$ array provides less heat transfer than the single jet at the same total mass flow rate. Average heat transfer coefficients for the $4 \times 3.18 \mathrm{~mm}$ array and the single jet shown in Fig. 12 were 301 and $595 \mathrm{~W} / \mathrm{m}^{2} \mathrm{~K}(\mathrm{H} / \mathrm{d}$ $=4)$ and 327 and $559 \mathrm{~W} / \mathrm{m}^{2} \mathrm{~K}(H / d=0.5)$, respectively. However, because the array jets operate at a quarter of the velocity, the pressure drop (and thus pumping power) is significantly lower for

Table 1 Measured pressure drop values $(\mathrm{Pa})$ for the jet arrays. (Selected single-jet results are also included for comparisons at constant flow rate.)

\begin{tabular}{c|c|c|c|c|c|c|c}
$\begin{array}{c}\text { Orifice } \\
\text { Configuration }\end{array}$ & 1666 & 5000 & $\mathbf{8 2 5 0}$ & 10000 & 15000 & 20000 & 33000 \\
\hline \hline $\begin{array}{c}9 \times 1.59 \mathrm{~mm} \\
(\mathbf{S} / \mathrm{d}=4)\end{array}$ & 311 & 1807 & - & 6432 & 13202 & - & - \\
\hline $\mathbf{1 . 5 9} \mathrm{mm}$ & - & 1744 & - & 5841 & 11174 & - & - \\
\hline $\begin{array}{c}4 \times 3.18 \mathrm{~mm} \\
(\mathbf{S} / \mathrm{d}=\mathbf{3 , 4 )}\end{array}$ & - & 486 & 1250 & 1818 & 3861 & 6636 & - \\
\hline $\mathbf{3 . 1 8} \mathrm{mm}$ & - & 585 & - & 1880 & 3978 & 6603 & 15070
\end{tabular}

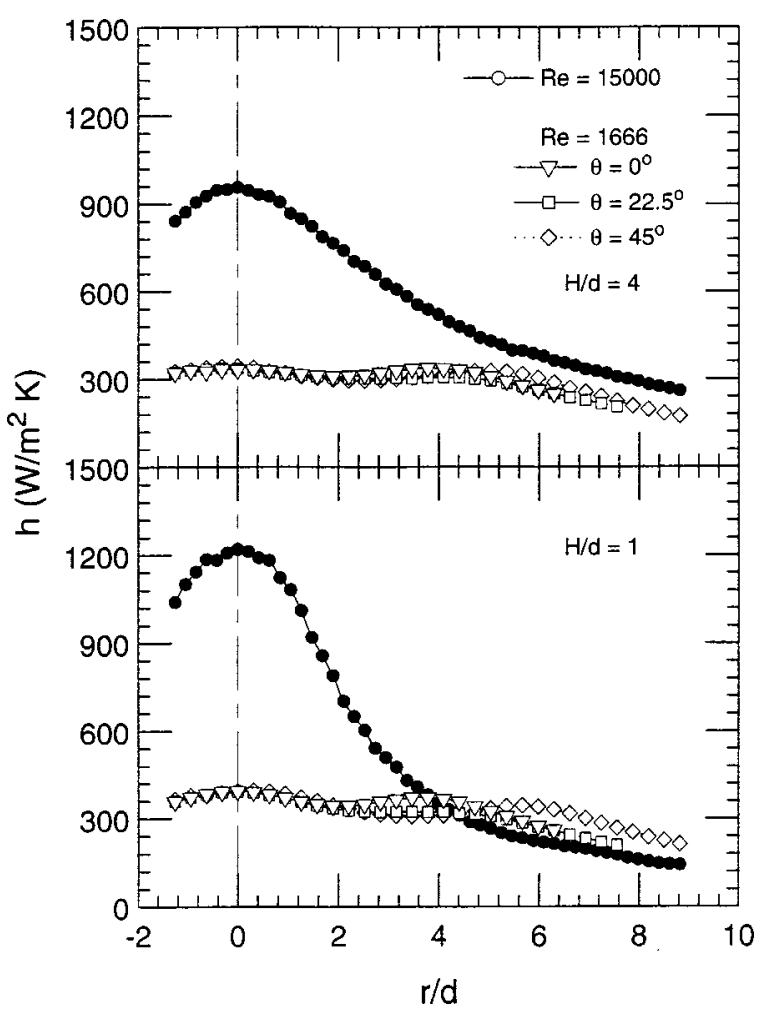

Fig. 13 Comparison of heat transfer coefficients for a single $1.59 \mathrm{~mm}$ jet (solid symbols) with the $9 \times 1.59 \mathrm{~mm}$ jet array (open symbols) at constant flow rate $\left(\dot{m} \approx 3.4 \times 10^{-04} \mathrm{~kg} / \mathrm{s}\right)$ at $H / d=4$ (top) and 1 (bottom)

the array (486 $\mathrm{Pa}$ for the array versus $6603 \mathrm{~Pa}$ for the single jet). At a higher mass flow rate $\left(\dot{m} \approx 15 \times 10^{-4} \mathrm{~kg} / \mathrm{s}\right.$, data not shown), the average heat transfer coefficients for the array and single jet were 416 and $792 \mathrm{~W} / \mathrm{m}^{2} \mathrm{~K}(H / d=4)$ and 488 and $751 \mathrm{~W} / \mathrm{m}^{2} \mathrm{~K}$ $(H / d=0.5)$, respectively; again the single jet requires a twelve times larger pressure drop than the jet array. The trade-off for a single $1.59 \mathrm{~mm}$ jet compared to the $9 \times 1.59 \mathrm{~mm}$ array at the same mass flow rate is shown in Fig. 13. For example, at $H / d=1$, the average heat transfer for the single jet and the nine-jet array are comparable ( 278 and $281 \mathrm{~W} / \mathrm{m}^{2} \mathrm{~K}$, respectively); however, nearly 36 times the pressure drop (and pumping power) is required for the single jet relative to the array to remove the same amount of heat!

The choice of whether to use a single jet or multiple jets for a given heat-removal application depends, among other factors, on whether the design constrains are on the allowable flow rate or the pressure drop.

\section{Conclusions}

The local heat transfer coefficient distributions in confined multiple-air jet impingement were obtained as a function of orifice-target plate spacing, Reynolds number, and multiple-orifice arrangement. Pressure drop values for the jet arrays and the corresponding single jets were also measured. In all multiple-jet cases, a decrease in the orifice-target spacing was found to increase the heat transfer coefficients, with the effect being stronger at the higher Reynolds numbers. The central jet in the nine-jet array had considerably larger stagnation-region heat transfer coefficients than the corresponding single jet at the same Reynolds number and orifice-target spacing; the average heat transfer coefficients for the jet array were significantly higher than for the single jet. For the four-jet array, however, the stagnation-region heat transfer coefficients for each of the four jets were comparable to the corresponding single-jet data, although the average heat 
transfer coefficient was somewhat higher for the jet array. The effect of changing the interjet spacing from four to three nozzle diameters resulted in higher heat transfer coefficients in the interior of the heat source, and lower values towards the edges; however, the average heat transfer coefficient was largely unaffected by the change in interjet spacing. Correlations for the areaaveraged heat transfer were proposed as functions of the jet Reynolds number, fluid Prandtl number, and orifice-target plate spacing, and compared with others in the literature.

\section{Acknowledgment}

Funding for this work provided by Cray Research of Chippewa Falls, Wisconsin, is greatly appreciated.

\section{Nomenclature}

$$
\begin{aligned}
& A_{h}=\text { heated area of heater, } \mathrm{m}^{2} \\
& A_{i}=\text { incremental area of heated surface, } \mathrm{m}^{2} \\
& A_{r}=\text { area of impingement region, } 4(1.9 \mathrm{~d})^{2} / D_{e}{ }^{2}, \mathrm{~m}^{2} \\
& d=\text { orifice diameter, } \mathrm{m} \\
& D_{e}=\text { effective heater diameter, } \mathrm{m} \\
& f=\text { open area ratio, } n\left(\pi d^{2}\right) /\left(4 A_{h}\right) \\
& \mathbf{G}=\text { factor in Martin [18] correlation } \\
& H=\text { orifice-target spacing, } \mathrm{m} \\
& h=\text { local convective heat transfer coefficient, } \mathrm{W} / \mathrm{m}^{2} \mathrm{~K} \\
& \bar{h}=\text { area-averaged heat transfer coefficient, } \mathrm{W} / \mathrm{m}^{2} \mathrm{~K} \\
& k=\text { fluid thermal conductivity, } \mathrm{W} / \mathrm{mK} \\
& K=\text { factor in Martin [18] correlation } \\
& l=\text { orifice thickness, } \mathrm{m} \\
& \dot{m}=\text { mass flow rate, } \mathrm{kg} / \mathrm{s} \\
& n=\text { number of jets } \\
& \overline{\mathrm{Nu}}=\text { area averaged Nusselt number }(\bar{h} d / k) \\
& \overline{\mathrm{Nu}}_{s}=\text { average Nusselt number based on interjet spacing } \\
& (\bar{h} S / k) \\
& \operatorname{Pr}=\text { fluid Prandtl number } \\
& Q_{\text {in }}=\text { power supplied to heater, } W \\
& Q_{\text {loss }}=\text { power lost by conduction and radiation, } W \\
& q_{s}^{\prime \prime}=\text { convected heat flux, }\left(Q_{\text {in }}-Q_{\text {loss }}\right) / A_{h}, \mathrm{~W} / \mathrm{m}^{2} \\
& r=\text { radial distance from stagnation point, } \mathrm{m} \\
& \operatorname{Re}=\text { Reynolds number }(U d / \nu) \\
& \operatorname{Re}_{\mathrm{S}}=\text { Reynolds number based on interjet spacing } \\
& (U S / \nu) \\
& S=\text { spacing between centers of adjacent orifices, } \mathrm{m} \\
& T_{j}=\text { jet exit temperature, }{ }^{\circ} \mathrm{C} \\
& T_{s}=\text { local heater surface temperature, }{ }^{\circ} \mathrm{C} \\
& \bar{T}_{s}=\text { surface-averaged heater temperature, }{ }^{\circ} \mathrm{C} \\
& T_{s i}=\text { local surface temperature measured for a band of } \\
& \mathrm{U}=\text { average air velocity at jet exit, } \mathrm{m} / \mathrm{s} \\
& \nu=\text { kinematic viscosity, } \mathrm{m}^{2} / \mathrm{s}
\end{aligned}
$$

$$
\theta=\begin{aligned}
& \text { angular position of measurement rays along the } \\
& \text { heated surface }
\end{aligned}
$$

\section{References}

[1] Schroeder, V. P., and Garimella, S. V., 1998, "Heat transfer from a discrete heat source in confined air jet impingement," Heat Transfer 1998, Procs. International Heat Transfer Conference, Vol. 5, pp. 451-456.

[2] Garimella, S. V., and Rice, R. A., 1995, "Confined and submerged liquid jet impingement heat transfer," ASME J. Heat Transfer, 117, pp. 871-877.

[3] Garimella, S. V., and Nenaydykh, B., 1996, "Nozzle-geoemtry effects in liquid jet impingement heat transfer,' Int. J. Heat Mass Transf., 39, pp. 29152923.

[4] Fitzgerald, J. A., and Garimella, S. V., 1998, "A study of the flow field of a confined and submerged impinging jet,' Int. J. Heat Mass Transf., 41, pp. $1025-1034$.

[5] Huber, A. M., and Viskanta, R., 1994, "Convective heat transfer to a confined impinging array of air jets with spent air exits," ASME J. Heat Transfer, 116, pp. $570-576$.

[6] Huber, A. M., and Viskanta, R., 1994, "Effect of jet-jet spacing on convective heat transfer to confined, impinging arrays of axisymmetric air jets," Int. J. Heat Mass Transf., 37, pp. 2859-2869.

[7] Obot, N. T., and Trabold, T. A., 1987, "Impingement heat transfer within arrays of circular jets: Part 1-Effects of minimum, intermediate, and complete crossflow for small and large spacings,' ASME J. Heat Transfer, 109, pp. 872-879.

[8] Goldstein, R. J., and Timmers, J. F., 1982, “Visualization of heat transfer from arrays of impinging jets,'” Int. J. Heat Mass Transf., 25, pp. 1857-1868.

[9] Gardon, R., and Cobonpue, J., 1962, "Heat transfer between a flat plate and jets of air impinging on it,' Int. Dev. Heat Mass Transfer, Procs. 2nd Int. Heat Transfer Conf., pp. 454-460.

[10] Behbahani, A. I., and Goldstein, R. J., 1983, 'Local heat transfer to staggered arrays of impinging circular air jets,'” ASME J. Eng. Power, 105, pp. 354360.

[11] Pan, Y., and Webb, B. W., 1994, "Heat transfer characteristics of arrays of free-surface liquid jets," General Papers in Heat and Mass Transfer, Insulation, and Turbomachinery, ASME HTD-Vol. 271, pp. 23-28

[12] Slayzak, S. J., Viskanta, R., and Incropera, F. P., 1994, "Effects of interactions between adjoining rows of circular, free-surface jets on local heat transfer from the impingement surface," ASME J. Heat Transfer, 116, pp. 88-95.

[13] Hollworth, B. R., and Dagan, L., 1980, "Arrays of impinging jets with spent fluid removal through vent holes on the target surface-Part 1: Average heat transfer,', ASME J. Eng. Power 102, pp. 994-999.

[14] Schroeder, V. P., 1997, "Heat Transfer from a Discrete Heat Source in Confined Air Jet Impingement with Single and Multiple Orifices,' M.S. thesis, University of Wisconsin-Milwaukee.

[15] Striegl, S. A., and Diller, T. E., 1984, "The effect of entrainment temperature on jet impingement heat transfer,' ASME J. Heat Transfer, 106, pp. 27-33.

[16] Sun, H., Ma, C. F., and Nakayama, W., 1993, "Local characteristics of convective heat transfer from simulated microelectronic chips to impinging submerged round water jets,"' ASME J. Electron. Packag., 115, pp. 71-77.

[17] Obot, N. T., Mujumdar, A. S., and Douglas, W. J. M., 1980, "Design correlations for heat and mass transfer under various turbulent impinging jet configurations," Drying, pp. 388-402.

[18] Martin, H., 1977, "Heat and mass transfer between impinging gas jets and solid surfaces," Adv. Heat Transfer, 13, pp. 1-60.

[19] Obot, N. T., Douglas, W. J. M., and Mujumdar, A. S., 1982, "Effect of semi-confinement on impingement heat transfer," Procs. 7th Int. Heat Transfer Conf., Vol. 3, pp. 395-400.

[20] Ashforth-Frost, S., Jambunathan, K., and Whitney, C. F., 1997, "Velocity and turbulence characteristics of a semiconfined orthogonally impinging slot jet," Exp. Therm. Fluid Sci., 14, pp. 60-67.

[21] Fitzgerald, J. A., and Garimella, S. V., 1997, "Flow field effects on heat transfer in confined jet impingement," ASME J. Heat Transfer 119, pp. 630632. 